\title{
MORPHOMETRIC ANALYSIS OF CRUCIATE LIGAMENTS
}

\section{Geetha rani B.G *1, Varsha Mokhasi ${ }^{2}$, Tamsir Rong ${ }^{3}{ }^{3}$.}

${ }^{{ }^{1} 1}$ Assistant Professor, Department of Anatomy, Vydhehi Institute of Medical Sciences, Bangalore, Karnataka, India.

${ }^{2}$ Professor \& HOD, Department of Anatomy, Vydhehi Institute of Medical Sciences, Bangalore, Karnataka, India.

${ }^{3}$ Assistant Professor, Department of Radiology, Vydhehi Institute of Medical Sciences, Bangalore, Karnataka, India.

\section{ABSTRACT}

Introduction: Anterior cruciate ligaments $(A C L)$ and posterior cruciate ligaments $(P C L)$ are tough band of fibrous structures extending between tibia and femur. Cruciate ligaments are at risk of injury in sports personnel. Injured ligaments are treated by reconstruction surgeries which require the morphometric understanding. Therefore, this study intended to find the length and width of $A C L$ and $P C L$ in cadavers and by MRI in healthy individuals.

Material and methods: Thirty embalmed cadaver knees were dissected to expose the ligaments. Length and width of the ligaments was measured by the Vernier's calipers. Thirty MRIs of knee joint with no previous detected knee pathology were obtained and reviewed. The data was tabulated for statistical analysis. Student ${ }^{\prime} t^{\prime}$ test was used for comparison. $\mathrm{P}$ value $<0.05$ was considered as statistically significant.

Results: In the cadavers, $A C L$ was significantly longer than $P C L$ in length $(p<0.014)$. $P C L$ width was larger than $A C L$ width $(\mathrm{p}<0.001)$.

Conclusion: The present study contributes to the relative morphometric data on $A C L$ and $P C L$ and stresses that $\mathrm{PCL}$ is shorter and wider than ACL making it a more stable structure.

KEY WORDS: Morphometry, Anterior Cruciate Ligaments, Posterior Cruciate Ligament.

Corresponding Author: Dr Geetha rani B.G, Assistant Professor, Department of Anatomy, Vydhehi Institute of Medical Sciences, Bangalore 560066, Karnataka, India.

Mobile No: 9964068258 E-Mail: lalithgeetha246@gmail.com

\begin{tabular}{|c|c|c|c|}
\hline Access this Article online & \multicolumn{3}{|c|}{ Journal Information } \\
\hline \multirow[t]{3}{*}{ Quick Response code } & \multicolumn{3}{|c|}{$\begin{array}{l}\text { International Journal of Anatomy and Research } \\
\begin{array}{l}\text { ICV for 2016 ISSN (E) 2321-4287 | ISSN (P) 2321-8967 }\end{array}\end{array}$} \\
\hline & \multicolumn{3}{|c|}{ Article Information } \\
\hline & $\begin{array}{l}\text { Received: } 10 \text { Oct } 2019 \\
\text { Peer Review: } 14 \text { Oct } 2019\end{array}$ & $\begin{array}{l}\text { Accepted: } 11 \text { Nov } \\
\text { Published (0): } 05\end{array}$ & $\begin{array}{l}19 \\
\text { c } 2019\end{array}$ \\
\hline DOI: 10.16965/ijar.2019.332 & Revised: None & Published (P): 05 & 2019 \\
\hline
\end{tabular}

\section{INTRODUCTION}

Knee joint is a complex synovial joint and the problems related to it are complex due to its associated ligamentous injuries. In 1892, Bugnion enchantingly compares the knee and femoral condyles to a chariot with tilted wheels stabilized by internal oblique guides, the cruciate ligament [1]. Cruciate ligaments are tough band of fibrous structures in the knee joint extending between Tibia and Femur as they twist around each other in a longitudinal axis during attachment to the opposing surfaces of same bones i.e Femur \& Tibia. They are further named as anterior and posterior based on their attachments on tibia. Anterior Cruciate ligament $(\mathrm{ACL})$ and Posterior cruciate ligament $(\mathrm{PCL})$ play important role in providing stability to the knee joint [2]. Anterior cruciate ligament ( $A C L)$ 
extends proximally from medial surface of lateral femoral condyle \& the intercondylar notch of femur running anteriorly, distally and medially to get attached to a wide depressed area anterior and lateral to the medial tibial tubercle in the intercondylar fossa of Tibia [3]. On magnetic resonance imaging ( $\mathrm{MRI}), A C L$ is best visualized on sagittal images because of oblique course. It appears with low signal intensity. Any discontinuity in its fibers results in edema and hemorrhage indicating a tear [4]. Further studies on $A C L$ is said to consist of two distinct bundles, the antero medial bundle which becomes taut at $90^{æ \%}$ of flexion. The posterolateral bundle becomes taut at full extension. ACL primarily provides approximately $85 \%$ of the resistance to anterior tibial translation. Secondary functions include restraint to varus/valgus forces and also it provides rotational stability through the posterolateral bundle [4].

Posterior cruciate ligament (PCL) originates from the posterior part of lateral surface of medial femoral condyle in intercondylar notch runs distally, posteriorly and gets inserted to a depression posterior to the intra articular upper surface of Tibia. It also sends a slip to blend with the posterior horn of lateral meniscus. The $P C L$ is split into two functional bundles; the anterolateral bundle (ALB) and the posteromedial bundle (PMB). The ALB is tight at flexion, while the PMB is tight at extension [5]. On MRI, $\mathrm{PCL}$ is well visualized in both sagittal and coronal plane. $P C L$ appears with low signal intensity along with a hockey stick shape and more uniform than $A C L$ owing to the presence of a tighter and stronger investing sheath [6]. In addition, the $P C L$ is the primary stabilizer of the knees because it provides the central rotational axis and responds to $95 \%$ of the posterior displacement of the tibia over the femur. It also limits the varus and valgus as well as the external rotation of this joint [5].

The Cruciate ligaments often get injured in people who play sports like soccer, football, tennis, basketball, volleyball, or gymnastics. ACL injuries are due to non contact injuries that happen when the athletes stop and quickly change directions while they're running [7]. PCL injuries are contact injuries often due to a blow/ falling on the knee while it's bent (dash board injury) [8]. It is estimated that $\mathrm{ACL}$ and $\mathrm{PCL}$ injuries account for about $60 \%$ and $3 \%$ of the total knee injuries respectively. It may be due to the fact that PCL is almost twice as strong as $A C L$. It takes considerable force to rupture the PCL than it does the $A C L$ as the PCL has more abundant blood supply than ACL. Cruciate ligament injuries are treated by reconstruction surgeries. The systematic morphometric values of theses ligaments strongly influence the cruciate ligament reconstruction. Therefore, this study intended to study the length and width of $A C L$ and PCL. This study was also interested in correlating the anatomical findings with MRI conclusions.

\section{MATERIALS AND METHODS}

The study was conducted in the Department of Anatomy and Department of Radiology, Vydehi Institute of Medical Sciences\& Research Centre, Bangalore. Thirty two embalmed cadaver knees were obtained whose average age was 50 years without any gender differentiation. Exclusion criteria included any sign of previous surgery, ligament damage, cartilage deterioration, or joint contracture. Knees were stored at $20^{\circ} \mathrm{C}$ and thawed at room temperature overnight.

Dissection methodology: The knee was dissected according to Cunningham's manual of Anatomy. Initially skin, muscles, patellar and articular capsules were removed. Later, all soft tissues were removed from the specimens except the ligaments and the menisci. The synovial sheath covering the cruciate ligaments was carefully removed to preserve the menisco femoral ligaments. After exposure of the ligaments, each ligament was measured from proximal to distal attachment by the Vernier's calipers with knee in extended position. Their mid width circumference, the cross-sectional area at their site of attachment were measured. The ACL and PCL were transected at their tibial attachments and the tibia was disarticulated. The anterior and posterior meniscofemoral ligaments were meticulously dissected along their course adjacent to the PCL fibers.

Thirty MRIs of knee joint with no previous detected knee pathology were collected from Department of radiology, Vydehi Institute of Medical Sciences \& Research Centre. Sagittal 
planes (t2 weighted image) of knee MRI images were reviewed and their Femoral and Tibia measurements \& width was measured at mid portion. The data was tabulated for statistical analysis.

Statistical analysis: Mean and standard deviation for cadaveric findings and MRI findings were obtained for both the ligaments. Comparisons were made between $\mathrm{ACL}$ and PCL. Student ' $\mathrm{t}$ ' test and Mann Whitney $U$ test was used for comparison.

\section{RESULTS}

Fig. 1: Comparison of the length and width of the anterior cruciate ligament $(A C L)$ and posterior cruciate ligament (PCL).

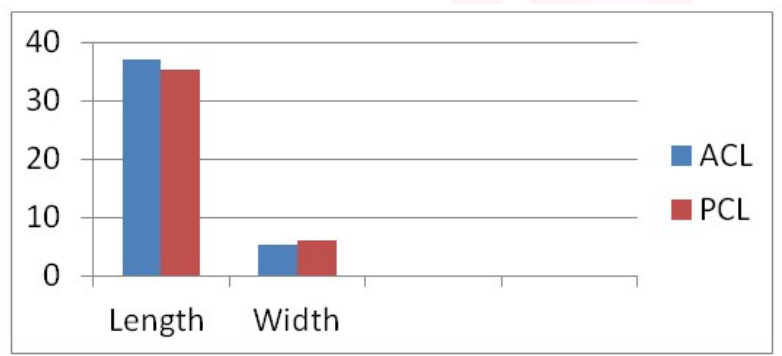

- Mean length of ACL $37.14 \mathrm{~mm}$ and width is $5.2 \mathrm{~mm}$

- Mean length of PCL $35.39 \mathrm{~mm}$ and width is $5.93 \mathrm{~mm}$

- Length - Independent Sample Test gives P value $<0.14$

Width - Mann Whitney Test gives $P$ value $<.0001$

Fig. 2: Photograph showing the anterior cruciate ligament and posterior cruciate ligament.
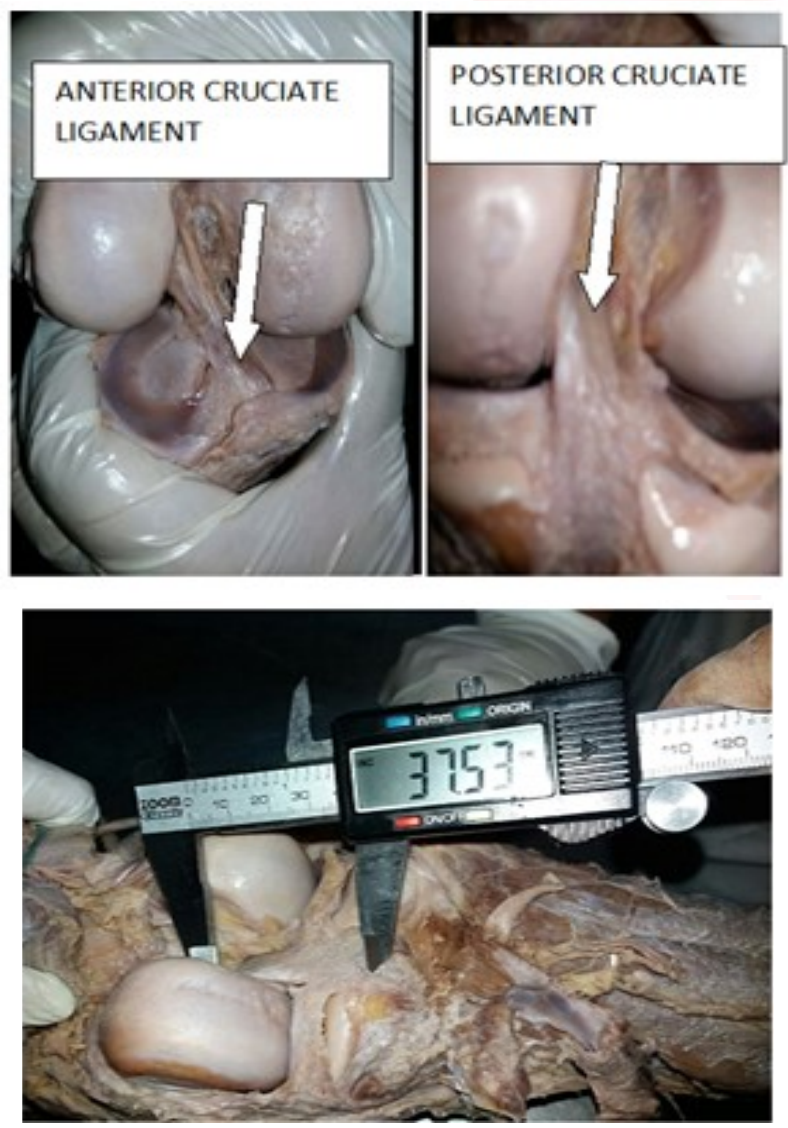

Int J Anat Res 2019, 7(4.3):7149-54. ISSN 2321-4287
Fig. 3: MRI of anterior cruciate ligament and posterior cruciate ligament.
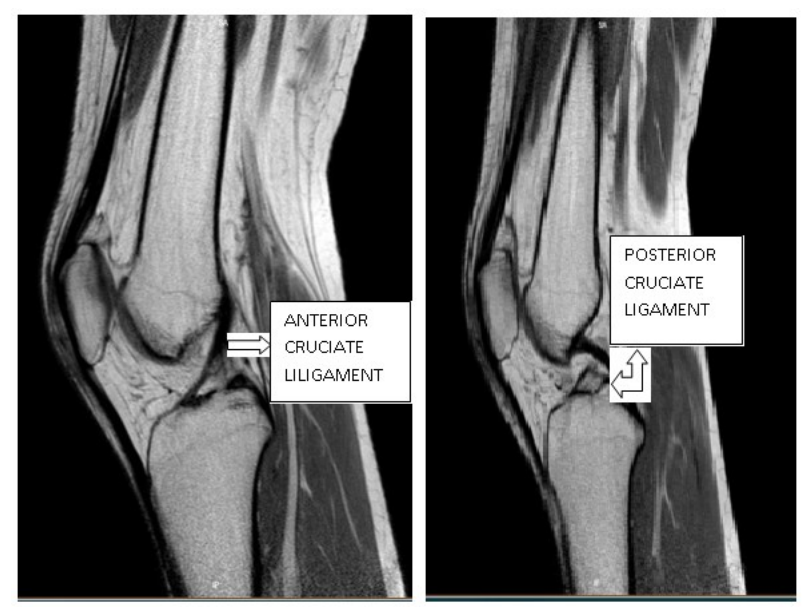

This study was done on 32 cadaveric knee joints and $30 \mathrm{MRIs}$ of apparently healthy knee joints. After their dissection to expose the anterior and posterior cruciate ligaments, measurements taken and statistical analysis was performed.

The findings are shown in figure $1,2 \& 3$. Figure 1 shows the comparison of length and width between $A C L$ and $P C L$ in cadavers and $M R I$ studies.

In the cadavers \& MRI measurements, it was observed that ACL was significantly ( $p$ value $0.014)$ longer than PCL in length. PCL width was larger than ACL width and the difference was statistically highly significant $(<0.001)$.

\section{DISCUSSION}

First known description of cruciate ligament is approximately 5000 years old. The anatomy of knee was mentioned in an Egypt papyrus scroll (3000BC) [9]. Hippocrates (460-377 BC) described subluxation of knee and correlated this to ligament injury. In 2nd century Galen of Pergamum gave first description of anatomy and function of the ACL. Next 1600 years, there was barely sufficient work on cruciate ligaments. Earlier, it was thought that cruciate ligaments were a part of nervous system and had contractile properties.

During last ten days of embryological period, the knee joint and its associated structures develop in an orderly process from the blastemal inter zone with no evidence of migration and it is essentially adult in orientation requiring only growth during the fetal development. At horizon 45 days of chronological age, 25-27 days of crown rump length there is appearance of 
cruciate ligaments along with chondrification of patella and appearance of menisci.

$\mathrm{ACL}$ injuries are due to noncontact injuries that happen when the athletes stop and quickly change directions while they're running. PCL injuries are contact injuries often due to a blow to the knee while it's bent like falling on the knee while it's bent. Cruciate ligament injuries are treated by reconstruction surgeries. These injuries result in joint effusion, altered movement, muscle weakness, reduced functional performance and long term clinical sequelae that include meniscal tears, chondral lesions and an increased risk of early onset post traumatic osteoarthritis within past two decades [10]. ACL injury frequently affects young, active individuals and females are at reported 2 to 10 fold greater risk than males playing the same sport. usually an allo or auto graft tendon taken either from the medial hamstrings or the middle $1 / 3$ of the patellar tendon but the reconstruction fails to restore normal joint kinematics and kinetics -mainly due to non-anatomic ligamentous insertion. Over last decade substantial effort has been made to make the surgical reconstruction more anatomical by altering tunnel position and introducing the concept of a double bundle reconstruction. Zantop et al concluded that if the graft was too long the tibial plug would protrude from the tunnel and if the graft was too short the graft would be buried and hence fixation with screw would not be possible. Therefore the length and thickness of the ligaments is important for choosing the graft [11].

Cruciate ligament tears are reconstructed by surgeries where the morphometric studies come in handy. Therefore, this study measured the length and width of $A C L$ and $P C L$ in cadavers and MRI. This study was also interested in correlating the anatomical findings with MRI conclusions.

It was seen in this study that each of the specimen follow a pattern on length and width of the cruciate ligaments both in cadavers and MRI studies. $A C L$ was longer than $P C L$ and $P C L$ was wider than ACL. The mean values also reflected the same. Statistical analysis showed that mean ACL length is significantly longer than $\mathrm{PCL}$ in cadaver specimens and on MRI studies. On the contrary PCL width is significantly larger than ACL in both cadaveric and MRI studies. Thus the short stout PCL with a larger area of attachment could explain it being less prone for injury than with the ACL.

This study also compared the results with that of the literature as shown in table $1 \& 2$. Girgis said that $A C L$ is attached to the posterior part of the medial surface of the lateral femoral condyle and to a wide depressed area in front and lateral to anterior tibial spine (medial intercondylar tubercle) with some fibres extending to the base [2]. Zantop described ACL to originate at the lateral femoral condyle and getting inserted at the medial and lateral tibial spine and to the area in between the spines [12]. However, another study mentioned that $A C L$ is attached to middle of intercondylar area and $\mathrm{ACL}$ pass beneath transverse meniscal ligament. Thus the descriptions about the proximal attachment were described to be similar but its distal attachment description varied around the eminences. Our study showed ACL to be attached on medial wall of lateral femoral condyle and getting attached to the intercondylar area behind the anterior horn of medial meniscus and in front of the eminences. Grays commented that bundles of $A C L$ are not visible to the naked eye but can be demonstrated by micro dissection techniques and named them as anteromedial, intermediate and Posterolateral [13]. Kweon accepted that ACL consisted of two discrete bundles [14]. Arnoczky, Petersen SP suggested that $A C L$ has multiple collagen bundles that give rise to multiple fascicular natures. Our study however showed $A C L$ to be consisting of two distinct bundle, (anteromedial bundle \& posterolateral bundle) on gross examination which became more evident on movement of knee joint. Amis AA et al said that PCL has an extensive origin on the roof and medial wall of intercondylar notch and a compact tibial insertion on superior surface of posterior tibial shelf. It was also described PCL as attached between posterior horns of the two menisci [15].

Our studies showed PCL to be attached to the lateral surface of the medial femoral condyle running downwards to attach behind the posterior horn of lateral menisci even extending beyond the posterior shelf of tibia, unlike amis findings we didn't find tibial attachments 
of PCL between the two horns of menisci.

Table 1: Length \&Width of anterior cruciate ligament.

\begin{tabular}{|l|c|c|}
\hline \multicolumn{1}{|c|}{ Author } & Length (mm) & Width (mm) \\
\hline Grays [13] & 38 & 11 \\
\hline Girgis FG et al [2] & $31-38$ & 10-Dec \\
\hline Odenstein et al [23] & $32 \pm 3$ & \\
\hline Yelicharla AK et al [21] & $\begin{array}{c}\text { Males: 43.5 } \\
\text { Females:41.9 }\end{array}$ & $\begin{array}{c}\text { Males: } 12.1 \\
\text { Females:11 }\end{array}$ \\
\hline Awadelsied MH [22] & 37 & 5 \\
\hline Iriuchishima T et al [24] & 32.28 & 3 \\
\hline This study & $37.14 \pm 3.916$ & $5.2 \pm 1.094$ \\
\hline
\end{tabular}

Table 2: Length \& width of posterior cruciate ligament.

\begin{tabular}{|l|c|c|}
\hline \multicolumn{1}{|c|}{ Author } & Length (mm) & Width (mm) \\
\hline Grays [13] & 38 & 13 \\
\hline Girgis FG et al [2] & 38 & 13 \\
\hline Covey DC [19] & 38 & 13 \\
\hline Pope T et al [25] & $22-38$ & 31 \\
\hline Yelicharla AK et alb[21] & Males: 35.9 & Males: 8.2 \\
& Females:37.1 & Females:9.1 \\
\hline This study & $35.39 \pm 3.738$ & $5.93 \pm 0.778$ \\
\hline
\end{tabular}

$\mathrm{PCL}$ is supported by two lesser ligaments, namely anterior menisco-femoral and posterior meniscofemoral ligaments. Both the ligaments are seen rarely together, but at least one of them is present in $93 \%$ of knees. Menisco-femoral ligaments act as a splint for the injured PCL to heal after its surgical reconstruction we also noted the presence of meniscofemoral ligament around the PCL ( $37 \%$, PMFL>AMFL). Grays said that $P C L$ is thicker and stronger than $A C L$ and with regard to bundles said that the anterolateral and posteromedial bundles are named (against convention) according to their femoral attachments [13]. Kennedy JC et al showed it to be twice as strong as the $A C L$ or the tibial collaterals [16]. Houghston JC et al have stressed that it is the fundamental stabilizer of the knee, as it is being at the axis of flexion extension and rotation [17]. In 1836, Weber brothers were the first to describe that there were two bundles in cruciate ligaments [1]. Amis $A A$ et al described $P C L$ as having antero-lateral and postero-medial functional bundles related to femoral attachment [15]. Saddler SC et al, in their study described three bundle in $\mathrm{PCL}$ namely, antero-lateral, postero-medial and an oblique reinforcing fibres, while Covey DC et al mentioned that PCL had four geographical fibers $[18,19]$. Tria AJ also mentions that $P C L$ is more of a compact fiber bundle [20]. Present study also saw two discrete bundles in PCL namely an anterolateral \& a posteromedial bundle.

Grays didn't study the difference in length of the ACL and PCL but described PCL broader than $A C L$. Yelicharla $A K$ et al studied the gender difference in $A C L$ and $P C L$ ligaments. He found that males had significantly longer $A C L$ length. He found no statistical difference in PCL length between males and females [21]. He also found ACL width was larger in males that were statistically significant. Yelicharla AK et al didn't compare the $A C L$ and $P C L$ statistically but it can be seen that mean $A C L$ is longer but narrower than mean PCL values in both males and females. Awadelsied $\mathrm{MH}$ found mean radiological length of ACL as $37 \mathrm{~mm}$ and mean ACL width as $8 \mathrm{~mm}$, which are similar to the findings of this study [22]. Future studies with huge sample size with good randomized method should be done to evaluate the anthropometric measurements.

\section{CONCLUSION}

As these ligaments are so much prone for injury and debility, their morphometrics is necessary for proper reconstruction and management preventing unnecessary iatrogenic injury. Future prospective studies with huge sample size with good randomized method should be done to evaluate the anthropometric measurements. The present study contributes to the relative morphometric data on $\mathrm{ACL}$ and $\mathrm{PCL}$ and stresses that PCL is shorter and wider than ACL making it a more stable structure. This study would be helpful in selecting the quantity and quality of graft for surgical reconstruction of cruciate ligaments.

\section{Conflicts of Interests: None}

\section{REFERENCES}

[1]. Pinskerova V, Maquet $P$, Freeman MA. Writings on the knee between 1836 and 1917. The Journal of bone and joint surgery. British volume. 2000 Nov;82(8):1100-2.

[2]. Girgis FG, Marshall JL, Monajem AR. The cruciate ligaments of the knee joint. Anatomical, functional and experimental analysis. Clinical orthopaedics and related research. 1975;106:216-31.

[3]. Arnoczky SP. Anatomy of the anterior cruciate ligament. Clinical orthopaedics and related research. 1983;172:19-25. 
[4]. Mink JH, Levy T, Crues 3rd JV. Tears of the anterior cruciate ligament and menisci of the knee: MR imaging evaluation. Radiology. 1988 Jun;167(3):76974.

[5]. Van Dommelen BA, Fowler PJ. Anatomy of the posterior cruciate ligament: a review. The American journal of sports medicine. 1989 Jan;17(1):24-9.

[6]. Rodriguez Jr W, Vinson EN, Helms CA, Toth AP. MRI appearance of posterior cruciate ligament tears. American Journal of Roentgenology. 2008 Oct;191(4):W155-9.

[7]. Kobayashi H, Kanamura T, Koshida S, Miyashita K, Okado T, Shimizu T, Yokoe K. Mechanisms of the anterior cruciate ligament injury in sports activities: a twenty-year clinical research of 1,700 athletes. Journal of sports science \& medicine. 2010 Dec; 9(4):669.

[8]. Fowler PJ, Messieh SS. Isolated posterior cruciate ligament injuries in athletes. The American journal of sports medicine. 1987; 15(6):553-7.

[9]. Strouhal E, Vachala B, Vymazalová H. The medicine of the ancient Egyptians. The American University in Cairo Press; 2014 Sep 30.

[10]. Nordenvall R, Bahmanyar S, Adami J, Mattila VM, Felländer-Tsai L. Cruciate ligament reconstruction and risk of knee osteoarthritis: the association between cruciate ligament injury and post-traumatic osteoarthritis. a population based nationwide study in Sweden, 1987-2009. PloS one. 2014 Aug 22;9(8):e104681.

[11]. Zantop T, Kubo S, Petersen W, MusahI V, Fu FH. Current techniques in anatomic anterior cruciate ligament reconstruction. Arthroscopy: The Journal of Arthroscopic \& Related Surgery. 2007 Sep 1;23(9):938-47.

[12]. Zantop T, Petersen W, Fu FH. Anatomy of the anterior cruciate ligament. Operative techniques in orthopaedics. 2005 Jan 1;15(1):20-8.

[13]. Standring S, editor, Gray's Anatomy, the anatomical basis of clinical practice. 3. Edinburgh: Elsevier Churchill Livingstone; 2005: 1461

[14]. Kweon C, Lederman ES, Chhabra A. Anatomy and biomechanics of the cruciate ligaments and their surgical implications. InThe multiple ligament injured knee 2013 (pp. 17-27). Springer, New York, NY.

[15]. Amis AA, Dawkins GP. Functional anatomy of the anterior cruciate ligament. Fibre bundle actions related to ligament replacements and injuries. Bone \& Joint Journal. 1991 Mar 1; 73(2):260-7.
[16]. Kennedy JC, Fowler PJ, Peltier LF. Medial and anterior instability of the knee: an anatomical and clinical study using stress machines. Clinical Orthopaedics and Related Research (1976-2007). 1995 Dec 1;321:3-9.

[17]. Hughston JC, Degenhardt TC. Reconstruction of the posterior cruciate ligament. Clinical Orthopaedics and Related Research ${ }^{\circledR} .1982$ Apr 1;164:59-77.

[18]. Saddler SC, Noyes FR, Grood ES, Knochenmuss DR, Samir Hefzy M. Posterior cruciate ligament anatomy and length-tension behavior of PCL surface fibers. American Journal of Knee Surgery. 1996;9:194-9.

[19]. Covey DC. Injuries of the posterolateral corner of the knee. JBJS. 2001 Jan 1;83(1):106-18.

[20]. Tria AJ. A contemporary bicruciate total knee arthroplasty. InSeminars in Arthroplasty 2017 Jun 1;28(2):65-70. WB Saunders.

[21]. Yelicharla AK, Gajbe U, Singh B. Morphometric Study on Cruciate Ligaments of Knee with Gender Differences: A Cadaveric Study. Asian Pac J Health Sci 2014; 1(3): 285-291

[22]. Awadelsied MH. Radiological Study of Anterior Cruciate Ligament of the Knee Joint in Adult Human and its Surgical Implication. Universal Journal of Clinical Medicine. 2015 Feb;3(1):1-5.

[23]. Odensten M, Gillquist J. Functional anatomy of the anterior cruciate ligament and a rationale for reconstruction. The Journal of bone and joint surgery. American volume. $1985 \mathrm{Feb}$;67(2):257-62.

[24].Iriuchishima T, Tajima G, Ingham SJ, Shen W, Smolinski P, Fu FH. Impingement pressure in the anatomical and nonanatomical anterior cruciate ligament reconstruction: a cadaver study. The American journal of sports medicine. 2010 Aug;38(8):1611-7.

[25]. Pope T, Bloem HL, Beltran J, Morrison WB, Wilson DJ. Musculoskeletal Imaging E-Book. Elsevier Health Sciences; 2014 Nov 3.

How to cite this article:

Geetha rani B.G, Varsha Mokhasi, Tamsir Rong P. MORPHOMETRIC ANALYSIS OF CRUCIATE LIGAMENTS. Int J Anat Res 2019;7(4.3):71497154. DOI: 10.16965/ijar.2019.332 